\title{
Blue-Light-Based White-LEDs based on a Novel Green-Yellow- Emitting Phosphor: Synthesis and Luminescence Properties
}

Qi Wang ${ }^{1}$,Meiling Xie ${ }^{1}$,Minghao Fang ${ }^{1,}$, Xiaowen Wu ${ }^{1}$,Yan'gai Liu ${ }^{1}$,Zhaohui Huang ${ }^{1}$,Kai $\mathrm{Xi}^{2}$ and Xin Min ${ }^{1,2,{ }^{*}}$

1. Beijing Key Laboratory of Materials Utilization of Nonmetallic Minerals and Solid Wastes, National Laboratory of Mineral Materials, School of Materials Science and Technology, China University of Geosciences, Beijing 100083, China

2. Department of Materials Science and Metallurgy, University of Cambridge, Cambridge CB3 OFS, UK

Authors to whom correspondence should be addressed.

\begin{abstract}
The development of white-light-emitting diodes (w-LEDs) makes it meaningful to develop novel highperformance phosphors excited by blue light. Herein, BiOCl: $\mathrm{Pr}^{3+}$ green-yellow phosphors were prepared via a high-temperature solid-state reaction method. The crystal structure, luminescent properties, lifetime, thermal quenching behavior, and quantum yield were studied in detail. The BiOCl: $\mathrm{Pr}^{3+}$ phosphors presented several emission peaks located in green and red regions, under excitation at $453 \mathrm{~nm}$. The CIE coordinates could be tuned along with the changed doping concentration with fair luminescence efficiency. The results also indicated that the optimized doping concentration of $\mathrm{Pr}^{3+}$ ions was at $\mathrm{x}=0.0075$ because of the concentration quenching behavior resulting from an intense exchange effect. When the temperature reached $150{ }^{\circ} \mathrm{C}$, the intensity of the emission peak at $495 \mathrm{~nm}$ could remain at $78 \%$ of that at room temperature. The activation energy of $0.20 \mathrm{eV}$ also confirmed that the $\mathrm{BiOCl}: \mathrm{Pr}^{3+}$ phosphor exhibited good thermal stability. All these results indicate that the prepared products have potential to be used as a high-performance green-yellow-light-emitting phosphor for blue-light-based wLEDs.
\end{abstract}

Keywords:

green-yellow phosphor; BiOCl:Pr+; photoluminescence; blue-light-based w-LEDs

\section{Introduction}

White-light-emitting diodes (w-LEDs) are potentially useful solid-state lighting devices because of their long service life, high luminous efficiency, energy saving, and environmental protection [1]. The widely used commercial w-LEDs are usually realized by combining blue light LED chips with YAG:Ce ${ }^{3+}$ yellow phosphors [2]. However, these commercial w-LEDs are not ideal due to their poor color rendering index, since the YAG:Ce ${ }^{3+}$ yellow phosphors lack the red-light emission peaks [3]. Many references have also been reported to improve their optical performance. The most common approaches are to add red-emitting phosphors [4] such as $\mathrm{Mn}^{4+}$-activated fluoride [5], oxide phosphors [6], and red-emitting CdSe/ZnS semiconductor quantum dots [7] to YAG:Ce ${ }^{3+}$ yellow-emitting phosphor. However, these approaches might result in the reabsorption among different phosphors, potentially reduce luminous efficiency, and limit their further application for w-LEDs [8]. Therefore, we think it is still of great significance to explore novel yellow phosphors with emission peaks in the green, yellow, and red regions under the excitation of blue light [9].

The $\mathrm{Pr}^{3+}$ ion, with a [Xe] $4 \mathrm{f}^{2}$ configuration, is one of the most special activators for phosphors due to its complex energy level scheme [10]. Through transition from different energy levels, the $\mathrm{Pr}^{3+}$ ion can emit light from visible to infrared light regions [11]. Thus, various phosphors doped with $\mathrm{Pr}^{3+}$ were prepared using different host 
materials, such as the $\mathrm{Gd}_{2} \mathrm{O}_{2} \mathrm{~S}: \operatorname{Pr}^{3+}[12], \mathrm{CaTiO}_{3}: \operatorname{Pr}^{3+}[13], \mathrm{BaMoO}_{4}: \operatorname{Pr}^{3+}[14], \mathrm{LaMgAl}_{11} \mathrm{O}_{19}: \operatorname{Pr}^{3+}[15]$, and $\beta-$ SiAlON: $\operatorname{Pr}^{3+}[16]$. If it is possible to dope only the $\operatorname{Pr}^{3+}$ ion-which can emit green and red emission lights simultaneously -into a novel host material, then the pure white light would be achieved by the excitation of blue light chips. This would be of great potential for application in w-LEDs [17].

It is also known that the $\mathrm{BiOX}(\mathrm{X}=\mathrm{Cl}, \mathrm{Br}, \mathrm{I})$ oxyhalide compounds have been widely used as catalysts in photocatalysis due to their strong intra-layer bonding force and weak interlayer van der Waals interaction [18]. These compounds usually consist of unique layered structures, which can efficiently separate the photogenerated electron-hole pairs through the internal electric fields and further improve the charge transfer from host to activation center. Thus, the doped rare-earth ions in BiOX oxyhalides host can absorb the activation more conveniently, and emit more intense emission peaks $[19,20]$. Moreover, the radius and charge of $\mathrm{Bi}^{3+}$ ion are like those of $\mathrm{Pr}^{3+}$ [21], suggesting that the $\mathrm{Bi}^{3+}$ ions could be substituted by $\mathrm{Pr}^{3+}$ ions in the BiOX lattice. All these studies further indicate that the compounds in BiOX oxyhalides family could be considered as host materials for $\mathrm{Pr}^{3+}$ doping. Among these oxyhalide-based phosphors, the rare-earth ion-doped $\mathrm{BiOCl}$ phosphors have been rarely prepared. Herein, the green-yellow-emitting phosphors BiOCl:Pr ${ }^{3+}$ were prepared for the first time. Their crystal structure, luminescent properties, lifetime, thermal quenching behavior, and quantum efficiency were studied in detail. Our investigation shows that the prepared products can be used as green-yellow phosphors for blue-light w-LEDs.

\section{Experimental Procedure}

\subsection{Material Synthesis}

$\mathrm{Bi}_{1-\mathrm{x}} \mathrm{OCl}: \mathrm{xPr}^{3+}(\mathrm{x}=0,0.0025,0.005,0.0075,0.01,0.03,0.05)$ phosphors were prepared by a high-temperature solid-state reaction method $[22,23,24]$. The stoichiometric ratio was calculated according to the following reaction equation:

$$
(1-x) \mathrm{Bi}_{2} \mathrm{O}_{3}+2 \mathrm{NH}_{4} \mathrm{Cl}+x \mathrm{Pr}_{2} \mathrm{O}_{3} \rightarrow 2 \mathrm{Bi}_{1-} \mathrm{OCl}_{2} \mathrm{XPr}^{3+}+2 \mathrm{NH}_{3}+\mathrm{H}_{2} \mathrm{O}
$$

(1)

$\mathrm{Bi}_{2} \mathrm{O}_{3}(99.9 \%), \mathrm{NH}_{4} \mathrm{Cl}(99.9 \%)$, and $\mathrm{Pr}_{2} \mathrm{O}_{3}(99.9 \%)$ were selected as raw materials. Because $\mathrm{NH}_{4} \mathrm{Cl}$ volatilizes at high temperature, $20 \mathrm{~mol} \%$ excess of $\mathrm{NH}_{4} \mathrm{Cl}$ was needed to compensate for the loss of volatilization. All these chemicals were evenly mixed in an agate mortar for about $30 \mathrm{~min}$. Afterwards, the mixed powders were put into an alumina crucible and heated in a muffle furnace at $540{ }^{\circ} \mathrm{C}$ for $1 \mathrm{~h}$. After natural cooling to room temperature, $\mathrm{Bi}_{1-\mathrm{XOCl}} \mathrm{xPr}^{3+}$ phosphors were taken out and ground into powder for further measurement. In order to verify the potentiality of $\mathrm{Bi}_{1-\mathrm{x}} \mathrm{OCl}: \mathrm{xPr}^{3+}$ phosphors on $\mathrm{w}$-LEDs, an w-LED device was fabricated, combining a blue GaN chip with the BiOCl:Pr ${ }^{3+}$ and self-made $\mathrm{K}_{2} \mathrm{GeF}_{6}: \mathrm{Mn}^{4}{ }^{+}$phosphors with a mass ratio of 100:1. Then, the mixed phosphors were dispersed in epoxy resin and coated on a blue GaN chip with an intense emission peak at 460 $\mathrm{nm}$. The coated chip was dried in an oven at $100^{\circ} \mathrm{C}$ for $3 \mathrm{~h}$, and finally the $\mathrm{w}$-LED device was obtained.

\subsection{Characterization Methods}

The powder X-ray diffraction (XRD) patterns of the samples were recorded by X-ray powder diffraction (AXS D8 Advance, Bruker, Corporation, Karlsruhe, Germany). The unit cell crystal structure of BiOCl was plotted by the VESTA program. Microstructure morphology was observed and studied by a field emission scanning electron microscope (FESEM, Zeiss supra-55, Oberkochen, Germany). Photoluminescence (PL) emission spectra and excitation (PLE) spectra were characterized by a FL-4600 fluorescence spectrophotometer (Hitachi, Tokyo, Japan), using a $150 \mathrm{~W}$ Xe lamp as an excitation source. The operating voltage of the photomultiplier tube of the spectrophotometer was $400 \mathrm{~V}$. Combining the same spectrophotometer with the self-made computer-controlled heating device, the PL spectra at different temperatures were tested. The decay behavior and lifetimes of PL were recorded by a time-resolved luminescence spectrometer (FS5, Edinburgh Instruments Ltd., Edinburgh, UK) combined with microsecond Xe flash and time-correlated single photon counter system. The quantum yield was characterized by an FLS920 fluorescence spectrophotometer (Edinburgh Instruments Ltd.) with an integrated 
sphere, and the absorption was measured with $\mathrm{BaSO}_{4}$ powder as reference.

\section{Results and Discussion}

\subsection{Phase Composition and Crystal Structure}

The phase composition of the products was measured by XRD. Figure 1a shows the XRD patterns of $\mathrm{Bi}_{1-\mathrm{x}} \mathrm{OCl}: \mathrm{xPr}^{3+}(\mathrm{x}=0,0.0025,0.005,0.0075,0.01,0.03,0.05)$ samples and the standard pattern of $\mathrm{BiOCl}$ (PDF NO. 82485). All the diffraction peaks of $\mathrm{Bi}_{1-\mathrm{x}} \mathrm{OCl}: \mathrm{xPr}^{3+}$ samples matched well with the $\mathrm{BiOCl}$ standard card. Almost no impurity peaks were presented. The addition of $\mathrm{Pr}^{3+}$ ions with different doping concentration had no significant effect on the crystalline structure of $\mathrm{BiOCl}$ host. Thus, it can be concluded that $\mathrm{Bi}_{1-\mathrm{x}} \mathrm{OCl}: \mathrm{xPr}^{3+}$ phosphors with stable structure can be easily prepared by this method.
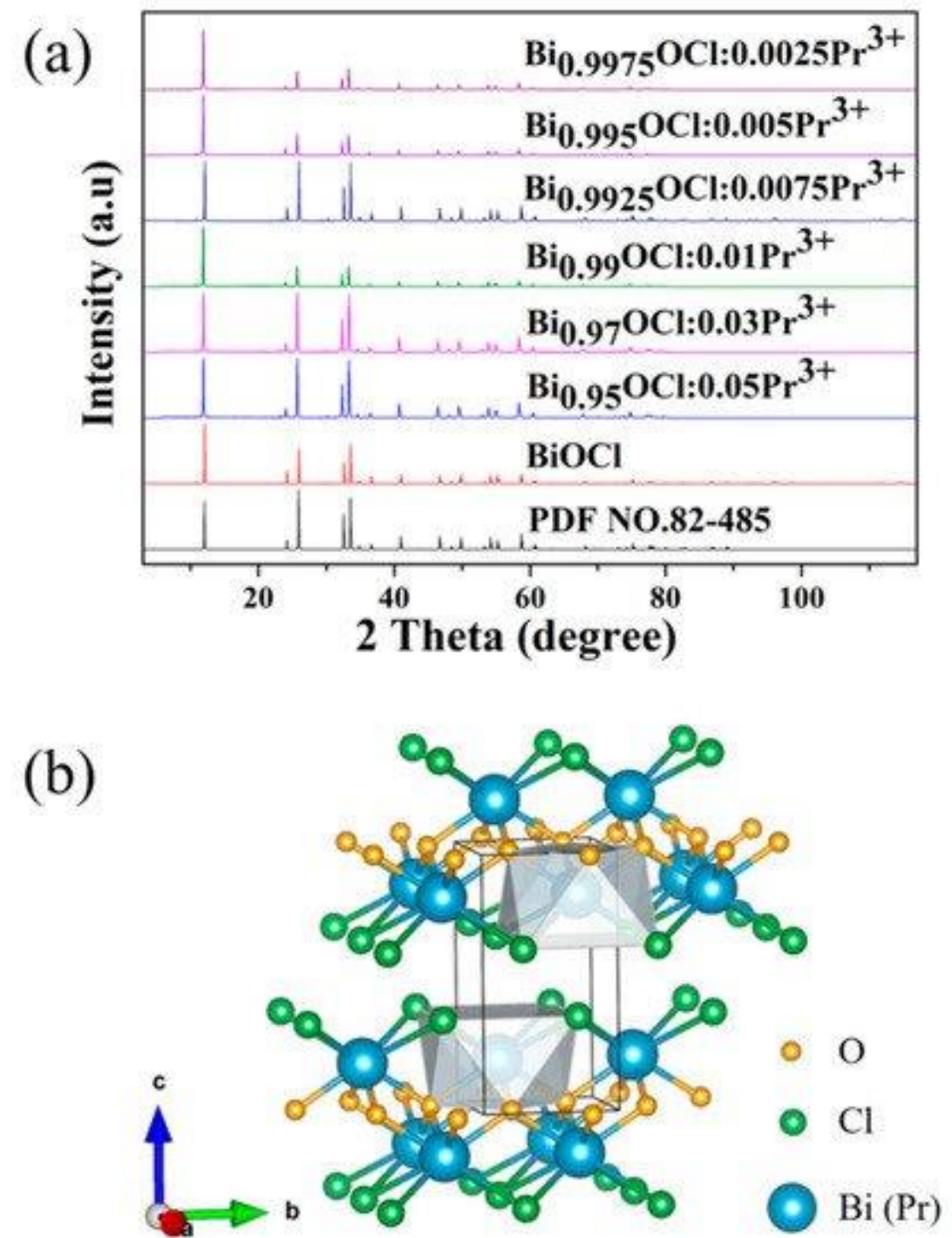

Figure 1. (a) XRD patterns of $\mathrm{Bi}_{1-\mathrm{x}} \mathrm{OCl}: \mathrm{xPr}^{3+}(\mathrm{x}=0,0.0025,0.005,0.0075,0.01,0.03,0.05)$ phosphors and the standard pattern (PDF NO. 82-485) of $\mathrm{BiOCl}$; (b) the unit cell crystal structure of $\mathrm{BiOCl}$.

The crystal structure of $\mathrm{BiOCl}$ is presented in Figure $1 \mathrm{~b}$. It is clear that the $\mathrm{BiOCl}$ compound was crystallized in a tetragonal matlockite structure. $\mathrm{The}^{\mathrm{Bi}^{3+}}$ atom coordinated to a square antiprism with four $\mathrm{O}$ atoms on one side and four $\mathrm{Cl}$ atoms on the other side. The [Cl-Bi-O-Bi-Cl] layers were stacked together by van der Waals interactions between $\mathrm{Cl}$ atoms along the c-axis $[25,26]$. The interplanar lattice spacing between two $\mathrm{Bi}^{3+}$ ions in $\mathrm{BiOCl}$ layers was found to be $4.85 \AA$. Since the radius of $\mathrm{Bi}^{3+}$ is similar to that of $\operatorname{Pr}^{3+}, \operatorname{Pr}^{3+}$ ions can be easily doped into the lattice and successfully replace the position of $\mathrm{Bi}^{3+}$ ions without any structural changes. The $\mathrm{XRD}$ results and the discussion of crystal structure indicate that the $\mathrm{Pr}^{3+}$ ion could be doped into the $\mathrm{BiOCl}$ host at $\mathrm{Bi}^{3+}$ sites. 


\subsection{PL properties of $B i_{1-x} \mathrm{OCl}: x \mathrm{Pr}^{3+}$ Phosphors}

Figure 2a shows the PLE $\left(\lambda_{\mathrm{em}}=495 \mathrm{~nm}\right)$ and PL $\left(\lambda_{\mathrm{ex}}=453 \mathrm{~nm}\right)$ spectra of $\mathrm{Bi} 0.9925 \mathrm{OCl}: 0.0075 \mathrm{Pr}^{3+}$ phosphor at room temperature. By monitoring the emission at $495 \mathrm{~nm}$, the excitation spectrum consisted of two peaks centered at 320 and $453 \mathrm{~nm}$, respectively. The excitation peak at $453 \mathrm{~nm}$ is attributed to the electron transition from energy level ${ }^{3} \mathrm{H}_{4}$ to ${ }^{3} \mathrm{P}_{2}$. The absorption band from 280 to $350 \mathrm{~nm}$ might result from the $4 \mathrm{f}-5 \mathrm{~d}$ characteristic transition absorption of $\mathrm{Pr}^{3+}$ ions [11]. In addition, the emission spectrum of $\mathrm{Bi} 0.9925 \mathrm{OCl}: 0.0075 \mathrm{Pr}^{3+}$ phosphor was composed of four peaks at 495,535,624, and $655 \mathrm{~nm}$, under excitation at $453 \mathrm{~nm}$. These emission peaks are attributed to the transitions of ${ }^{3} \mathrm{P}_{0} \rightarrow{ }^{3} \mathrm{H}_{4},{ }^{3} \mathrm{P}_{0} \rightarrow{ }^{3} \mathrm{H}_{5},{ }^{1} \mathrm{D}_{2} \rightarrow{ }^{3} \mathrm{H}_{4}$, and ${ }^{3} \mathrm{P}_{0} \rightarrow{ }^{3} \mathrm{~F}_{2}$, respectively $[27,28,29,30]$.
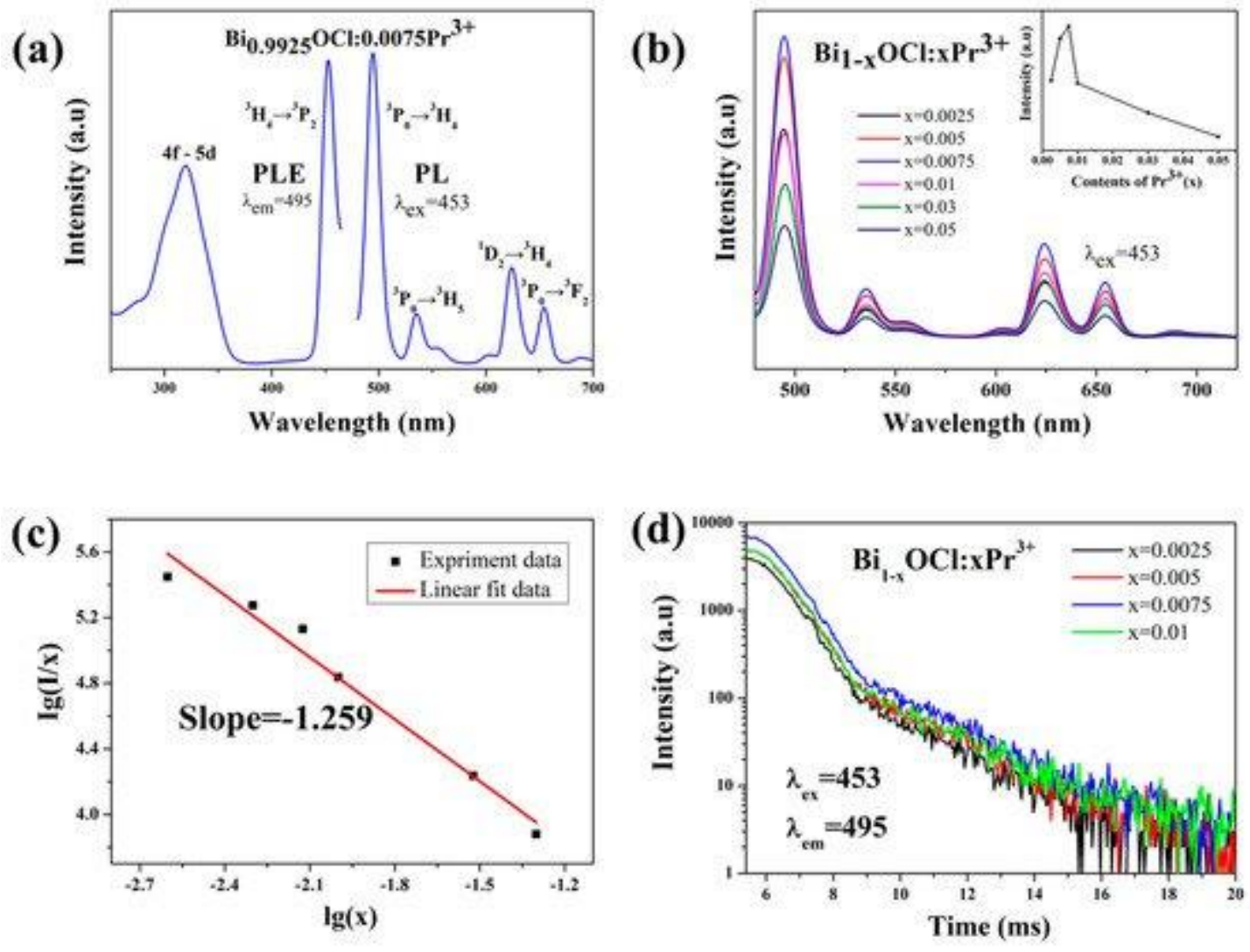

Figure 2. (a) Photoluminescence (PL) emission $\left(\lambda_{\mathrm{ex}}=453 \mathrm{~nm}\right)$ spectra and excitation (PLE) $\left(\lambda_{\mathrm{em}}=495 \mathrm{~nm}\right)$ spectra of a typical $\mathrm{Bi} 0.9925 \mathrm{OCl}: 0.0075 \mathrm{Pr}^{3+}$ sample at room temperature. $(b)$ Emission spectra $\left(\lambda_{\mathrm{ex}}=453 \mathrm{~nm}\right)$ and the relationship of the emission intensity on the content of $\operatorname{Pr}^{3+}$ of $\mathrm{Bi}_{--x} \mathrm{OCl}: \mathrm{xPr}^{3+}(\mathrm{x}=0.0025,0.005,0.0075,0.01,0.03$, and 0.05). (c) Linear fitting experiment data of $\lg (I / x)$ versus $\lg (x)$ for the $\mathrm{Bi}_{1-\mathrm{x}} \mathrm{OCl}: \mathrm{xPr}^{3+}(\mathrm{x}=0.0025,0.005,0.0075$, $0.01,0.03$, and 0.05) phosphors. (d) Decay curves of $\mathrm{Bi}_{1-\mathrm{x}} \mathrm{OCl}: \mathrm{xPr}^{3+}(\mathrm{x}=0.0025,0.005,0.0075$, and 0.01$)\left(\lambda_{\mathrm{ex}}=453 \mathrm{~nm}\right.$ and $\lambda_{\mathrm{em}}=495 \mathrm{~nm}$ ) with different concentrations.

The emission spectra of $\mathrm{Bi}_{1-\mathrm{x}} \mathrm{OCl}: \mathrm{xPr}^{3+}(\mathrm{x}=0,0.0025,0.005,0.0075,0.01,0.03,0.05)$ with different doping concentrations are shown in Figure $2 \mathrm{~b}$. With different $\operatorname{Pr}^{3+}$ concentrations, the emission spectra were similar with each other. The emission peaks were at the same position, but their intensities were different. The inset of Figure $2 \mathrm{~b}$ illustrates the dependence of emission intensity on $\mathrm{Pr}^{3+}$ concentration. With the increase of $\mathrm{Pr}^{3+}$ concentration, the emission intensity increased at first, reached the maximum when the doping concentration of $\operatorname{Pr}^{3+}$ ion was at $\mathrm{x}=0.0075$, then decreased with further increasing $\mathrm{Pr}^{3+}$ concentration. This phenomenon resulted from the concentration quenching effect. It is worth mentioning that the optimized doping concentration $x=0.0075$ is actually a very low concentration, which means that the BiOCl: $\mathrm{Pr}^{3+}$ phosphor could emit light efficiently with fewer activators. This has also been seldom seen before, which could markedly reduce the cost of phosphors for w-LEDs.

There are many reasons for concentration quenching, including multipolar interaction or exchange interaction. The interaction types between the two types of incentives can be calculated by the following formula [31,32]: 


$$
I / x=k\left(1+\beta(x)^{Q / 3}\right)^{-1}
$$

where $x$ is the concentration of $\operatorname{Pr}^{3+}$ activator, and $k$ and $\beta$ are constants. $I / x$ is the ratio of the emission intensity to the doping concentration of activator. The $Q$ value determines the interaction type for the concentration quenching effect. When the values of $Q$ are $3,6,8$, and 10, the interaction could be classified as exchange interactions, dipole-dipole, dipole-quadrupole, and quadrupole-quadrupole interactions, respectively. Thus, the results of $\lg (I / x)$ and $\lg (x)$ are presented in Figure 2c to obtain the $Q$ value. As shown in Figure 2c, the relationship between $\lg (I / x)$ and $\lg (x)$ was linear. After data fitting, $Q / 3$ was found to be 1.259. Therefore, the calculated $Q$ value is relatively close to the theoretical value of 3 , which represents that the concentration quenching mechanism for the $\mathrm{BiOCl}: \mathrm{Pr}^{3+}$ phosphors is exchange interaction.

The lifetime reflects the rate of the electron transiting from the maximum energy excited state to the ground state when the excitation light is removed. Figure $2 \mathrm{~d}$ shows the decay curves of $\mathrm{Bi}_{1-\mathrm{x}} \mathrm{OCl}: \mathrm{xPr}^{3+}(\mathrm{x}=0,0.0025,0.005$, $0.0075,0.01$ ) phosphors at $495 \mathrm{~nm}$, when excited at $453 \mathrm{~nm}$. The results show that the emission intensity decreased as time goes by. However, the decay curves remained stable with increasing $\operatorname{Pr}^{3+}$ concentration. All the decay curves of $\mathrm{Bi}_{1-\mathrm{x}} \mathrm{OCl}: \mathrm{xPr}^{3+}$ were well fitted by an exponential function [33]:

$$
\mathrm{It}=\mathrm{Ae}^{-\mathrm{t} \tau+\mathrm{I} 0}
$$

where $I_{t}$ and $I_{0}$ are emission intensities at time $t$ and initial time, respectively, $A$ is a constant, and $\tau$ is the lifetime for exponential components. According to the function, when the concentration $x$ values were 0.0025 , 0.005, 0.0075, and 0.01, the average lifetimes of $\mathrm{Bi}_{1-x} \mathrm{OCl}: \mathrm{xPr}^{3+}$ phosphors were found to be 1.12, 1.13, 1.14, and $1.14 \mathrm{~ms}$, respectively. These PL lifetimes of $\mathrm{Bi}_{1-\mathrm{x}} \mathrm{OCl}: \mathrm{xPr}^{3+}$ are relatively stable.

\subsection{Thermal Stability of BiOCl:Pr ${ }^{3+}$ Phosphors}

The thermal stability of phosphors is an important factor for their application in w-LEDs [34]. Figure 3a shows the emission spectra of $\mathrm{Bi} 0.9925 \mathrm{OCl}: 0.0075 \mathrm{Pr}^{3+}$ phosphors at different temperatures, under excitation at 453 $\mathrm{nm}$. As shown in Figure 3a, the PL intensity decreased with the increase of test temperatures. When the temperature reached $150{ }^{\circ} \mathrm{C}$, the emission intensity of the peak at $495 \mathrm{~nm}$ remained at about $78 \%$ of the intensity at room temperature. Moreover, the central positions of emission peaks were not changed with increasing temperatures. To further investigate the temperature dependence of the luminescence property, the activation energy $(\Delta E)$ was calculated by the Arrhenius equation [35]:

$$
\mathrm{I}(\mathrm{T})=\mathrm{I} 01+\mathrm{Ce}-\Delta \mathrm{EkT}
$$

(4)

where $I_{0}$ is the emission intensity of phosphors at room temperature, $I(T)$ is the intensity at different temperatures, $c$ is a constant, and $k$ is the Boltzmann constant $\left(8.629 \times 10^{-5} \mathrm{eV}\right)$. According to the equation, $\Delta E$ could be calculated by Arrhenius fitting of the emission intensity of the $\mathrm{Bi} 0.9925 \mathrm{OCl}: 0.0075 \mathrm{Pr}^{3+}$ phosphor at different temperatures. Further, the smaller activation energy, the better thermal stability. As shown in Figure $3 \mathrm{~b}$, the relationship between $\ln \left[I_{0} / I(T)-1\right]$ and $1 / k T$ was close to a straight line. The activation energy of $\mathrm{Bi} 0.925 \mathrm{OCl}: 0.0075 \mathrm{Pr}^{3+}$ phosphor is calculated to be $0.20 \mathrm{eV}$, which is comparable to that of the phosphors reported in References [36,37]. All these results indicate that the prepared Bi ${ }_{0.925} \mathrm{OCl}: 0.0075 \mathrm{Pr}^{3+}$ phosphor has good thermal stability, which could have positive effects on its practical application. 
(a)

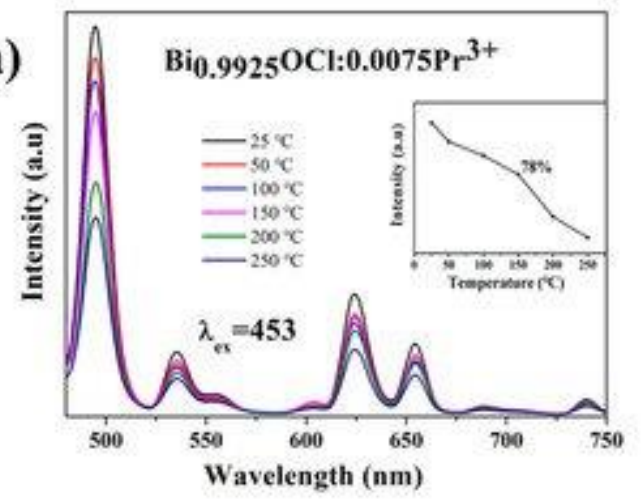

(b)

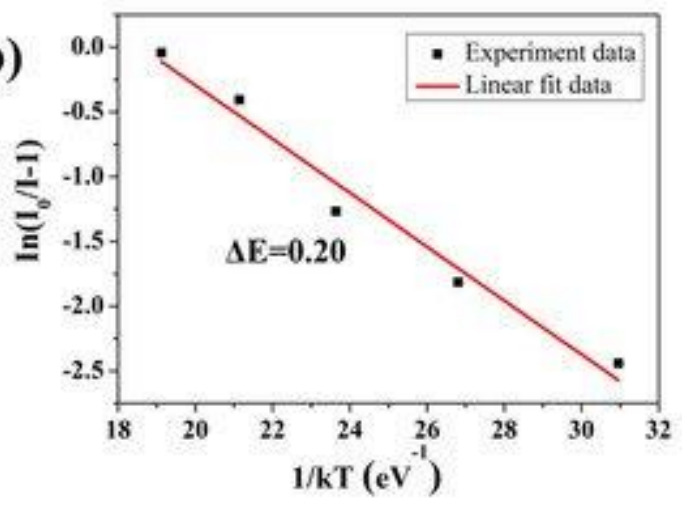

Figure 3. (a) PL spectra $\left(\lambda_{\text {ex }}=453 \mathrm{~nm}\right)$ of the $\mathrm{Bi} .9925 \mathrm{OCl}: 0.0075 \mathrm{Pr}^{3+}$ phosphor at different temperatures in the range of $25-250{ }^{\circ} \mathrm{C}$. The inset in (a) shows the changes of the PL intensities of $\mathrm{Bi} 0.9925 \mathrm{OCl}: 0.0075 \mathrm{Pr}^{3+}$ with temperature. (b) Dependence of $\ln \left[I_{0} / I(T)-1\right]$ on $1 / k T$ for the $\mathrm{Bi}_{0.9925} \mathrm{OCl}: 0.0075 \mathrm{Pr}^{3+}$ phosphor at the emission peaks of $495 \mathrm{~nm}$.

\subsection{Morphology and CIE Chromaticity Coordinates of Bi..9925OCl:0.0075Pr ${ }^{3+}$ Phosphor}

The quality of a phosphor powder is related not only to its chemical and phase purity but also to the particle size and morphology [38]. Figure 4a,b are the FESEM morphologies of $\mathrm{BiOCl}$ and $\mathrm{Bi} .9925 \mathrm{OCl}: 0.0075 \mathrm{Pr}^{3+}$ samples, respectively. It can be seen that all these particles were in irregular oblate spheres. The particle size was uniform and about 1-3 $\mu \mathrm{m}$. The average particle size was close to the optimal shape and size, which also had a positive impact on the luminescence performance.
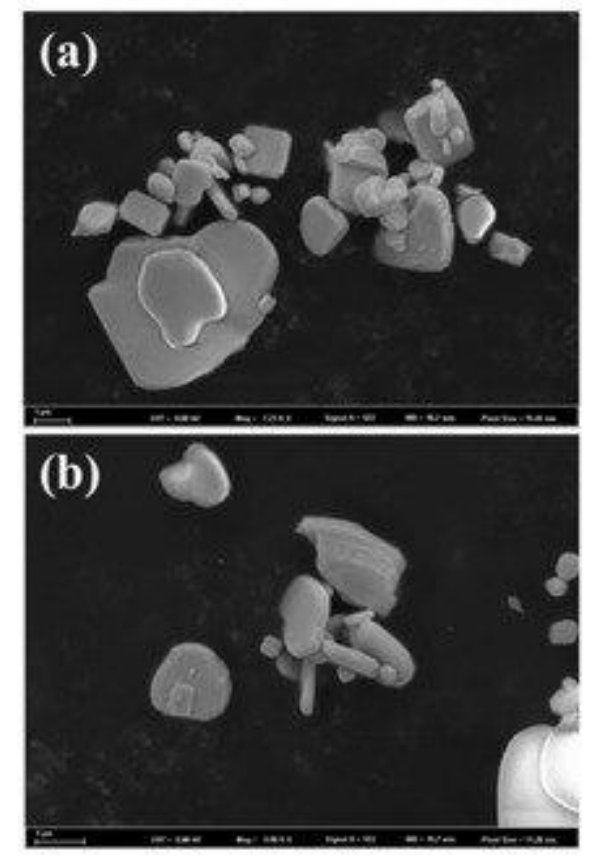

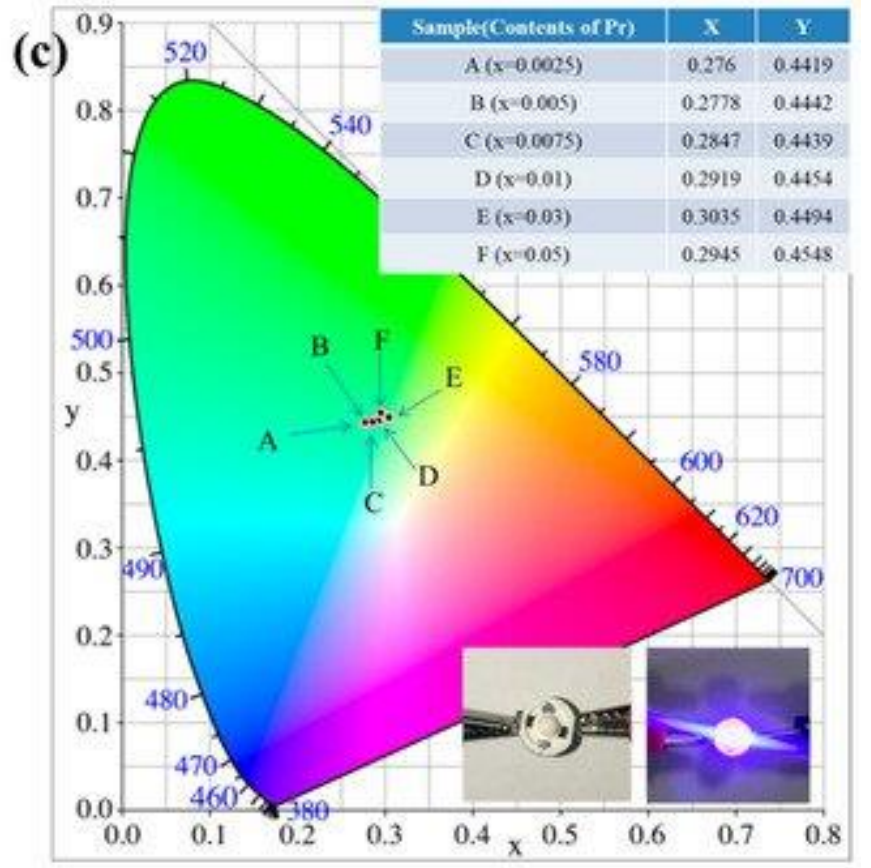
Figure 4. SEM micrographs of (a) $\mathrm{BiOCl}$ and (b) $\mathrm{Bi} 0.9925 \mathrm{OCl}: 0.0075 \mathrm{Pr}^{3+}$ phosphor. (c) The CIE chromaticity
coordinate of the $\mathrm{Bi}_{1-\mathrm{x}} \mathrm{OCl}: \mathrm{xPr}^{3+}(\mathrm{x}=0.0025,0.005,0.0075,0.01,0.03$, and 0.05) phosphors. The insets show the photographs of the fabricated white-light-emitting diode ( $w$-LED) device before (left) and after (right) switching on the power.

As shown in Figure 4c, the CIE chromaticity coordinates are presented to evaluate the color purity of the $\mathrm{Bi}_{1-\mathrm{x}} \mathrm{OCl}: \mathrm{xPr}^{3+}(\mathrm{x}=0.0025,0.005,0.0075,0.01,0.03$, and 0.05$)$ phosphors. Under the excitation at $453 \mathrm{~nm}$, the CIE coordinates of $\mathrm{Bi}_{1-x} \mathrm{OCl}: x \mathrm{Pr}^{3+}$ phosphor were calculated and dropped in the green-yellow light region. The CIE coordinate point gradually shifted to the yellow light region with increasing $\mathrm{Pr}^{3+}$ concentration. The PL quantum yields of the selected samples $\mathrm{Bi}_{1-\mathrm{x}} \mathrm{OCl}: \mathrm{xPr}^{3+}(\mathrm{x}=0.0025,0.005,0.0075,0.01)$ under excitation at $453 \mathrm{~nm}$ were measured to be $35.4 \%, 30.8 \%, 24.9 \%$, and $25.1 \%$. Although the quantum efficiency values of $\mathrm{BiOCl}: \mathrm{Pr}^{3+}$ phosphors were still lower than those of commercial phosphors, they could be increased through purification, surface coating treatment, or doping with other rare earth elements (e.g., Sm, Y, Li, and Bi) prior to 
further commercial applications $[39,40,41]$. Furthermore, the two insets show the photographs of the fabricated $\mathrm{w}$-LED device before (left) and after (right) switching on the power. It can be seen that the fabricated w-LED device could emit white light, combining with a blue light chip and some red phosphors. All these results indicate the $\mathrm{BiOCl}: \mathrm{Pr}^{3+}$ phosphors have good thermal stability, green-yellow spectrum, and light luminescence efficiency, which indicates that $\mathrm{BiOCl}: \mathrm{Pr}^{3+}$ can be used as a green-yellow phosphor material and widely used in blue-light-based w-LEDs.

\section{Conclusions}

In conclusion, the $\mathrm{BiOCl}: \mathrm{Pr}^{3+}$ phosphors were synthesized by a solid-state reaction method. Under excitation at $453 \mathrm{~nm}$, the $\mathrm{BiOCl}: \mathrm{Pr}^{3+}$ phosphors exhibited a green-yellow light with four emission peaks at 495, 535, 624, and $655 \mathrm{~nm}$. These emission peaks are attributed to the ${ }^{3} \mathrm{P}_{0} \rightarrow{ }^{3} \mathrm{H}_{4},{ }^{3} \mathrm{P}_{0} \rightarrow{ }^{3} \mathrm{H}_{5},{ }^{1} \mathrm{D}_{2} \rightarrow{ }^{3} \mathrm{H}_{4}$, and ${ }^{3} \mathrm{P}_{0} \rightarrow{ }^{3} \mathrm{~F}_{2}$ transitions, respectively. The optimized $\mathrm{Bi} 0.9925 \mathrm{OCl}: 0.0075 \mathrm{Pr}^{3+}$ phosphor was obtained with a CIE coordinate $(0.2847,0.4439)$. In addition, the $\mathrm{Bi} 0.9225 \mathrm{OCl}: 0.0075 \mathrm{Pr}^{3+}$ phosphor could also maintain a good thermal stability at high temperature. The intensity of emission peaks at $150{ }^{\circ} \mathrm{C}$ was about $78 \%$ of the initial intensity at room temperature. The quantum yield was measured to be $24.9 \%$. The results show that $\mathrm{BiOCl}: \mathrm{Pr}^{3+}$ phosphor is a green-yellow-light-emitting phosphor, which may be suitable for application in blue-light-based w-LEDs.

\section{Author Contributions}

Data curation, Y.L.; formal analysis, M.F., K.X. and X.M.; investigation, X.W. and Z.H.; methodology, M.F. and X.M.; writing - original draft, Q.W.; writing - review \& editing, M.X. and X.M.

\section{Funding}

This research was funded by the Fundamental Research Funds for the Central Universities (No. 26520173434) and the National Natural Science Foundation of China (No. 51572245 and No. 51702293).

\section{Conflicts of Interest}

The authors declare no conflict of interest.

\section{References}

1. Tian, L. L.; Zhang, W.; Yang, B.; Lu, P.; Zhang, M.; Lu, D.; Ma, Y. G.; Shen, J. C., Zinc(ii)-induced color-tunable fluorescence emission in the pi-conjugated polymers composed of the bipyridine unit: A way to get white-light emission. J Phys Chem B 2005, 109, 6944-6947.

2. Shen, F. Z.; He, F.; Lu, D.; Xie, Z. Q.; Xie, W. J.; Ma, Y. G.; Hu, B., Bright and colour stable white polymer light-emitting diodes. Semicond Sci Tech 2006, 21, L16-L19.

3. Zhen, H. Y.; Xu, W.; King, W.; Chen, Q. L.; Xu, Y. H.; Jiang, J. X.; Peng, J. B.; Cao, Y., White-light emission from a single polymer with singlet and triplet chromophores on the backbone. Macromol Rapid Comm 2006, 27, 2095-2100.

4. Tang, K. C.; Tseng, S. R.; Li, W. S.; Meng, H. F.; Horng, S. F.; Hsu, C. S., Broad band and white phosphorescent polymer light-emitting diodes in multilayer structure. Synthetic Met 2008, 158, 287-291.

5. Zhang, Y. F.; Xu, Z.; Zhang, F. J.; Wang, Y.; Zhao, S. L., White organic light emitting device with dyestuff dcjtb mended in polymer. Spectrosc Spect Anal 2008, 28, 760-762. 
6. Wang, R.; Peng, J.; Qiu, F.; Yang, Y. L.; Xie, Z. Y., Simultaneous blue, green, and red emission from diblock copolymer micellar films: A new approach to white-light emission. Chem Commun 2009, 6723-6725.

7. Zhang, T. H.; Gong, Z. C.; Que, L., A white-light source operated polymer-based micromachined fabry-perot chemo/biosensor. 2009 4th Ieee International Conference on Nano/Micro Engineered and Molecular Systems, Vols 1 and 2 2009, 181-184.

8. Wang, R.; Peng, J.; Qiu, F.; Yang, Y. L., Enhanced white-light emission from multiple fluorophores encapsulated in a single layer of diblock copolymer micelles. Chem Commun 2011, 47, 2787-2789

9. Watanabe, K.; Sakamoto, T.; Taguchi, M.; Fujiki, M.; Nakano, T., A chiral pi-stacked vinyl polymer emitting white circularly polarized light. Chem Commun 2011, 47, 10996-10998.

10. Willander, M.; Nur, O.; Zaman, S.; Zainelabdin, A.; Bano, N.; Hussain, I., Zinc oxide nanorods/polymer hybrid heterojunctions for white light emitting diodes. J Phys D Appl Phys 2011, 44.

11. Qin, L. J.; Zhu, Y. C.; Yang, H.; Ding, L.; Sun, F.; Shi, M.; Yang, S. P., White-light phosphorescence from binary coordination polymer nanoparticles. Mater Chem Phys 2013, 139, 345-349.

12. Wang, B. Z.; Zhang, X. P.; Liu, H. M., White-light-emitting diode based on a single-layer polymer. Aip Adv 2013, 3.

13. Song, H. J.; Shin, G. J.; Choi, K. H.; Lee, S.; Moon, D. K., White polymer light emitting diode materials introducing dendritic quinoxaline derivative: Synthesis, optical and electroluminescent properties. Synthetic Met 2014, 190, 1-7.

14. Wang, Z. W.; Gao, D. Z.; Ma, X. J.; Meng, J., White-light interferometry for measuring fuel pressure in icf polymermicrosphere targets. Fusion Sci Technol 2014, 66, 432-437.

15. Sun, C.; Zhang, Y.; Sun, K.; Reckmeier, C.; Zhang, T. Q.; Zhang, X. Y.; Zhao, J.; Wu, C. F.; Yu, W. W.; Rogach, A. L., Combination of carbon dot and polymer dot phosphors for white light-emitting diodes. Nanoscale 2015, 7, 12045-12050.

16. Taudt, C.; Baselt, T.; Oreski, G.; Hirschl, C.; Koch, E.; Hartmann, P., Cross-linking characterization of polymers based on their optical dispersion utilizing a white-light interferometer. Proc Spie 2015, 9525.

17. Roberts, R. J.; Le, D.; Leznoff, D. B., Color-tunable and white-light luminescence in lanthanide dicyanoaurate coordination polymers. Inorg Chem 2017, 56, 7948-7959.

18. Chen, S. A.; Chang, E. C.; Chuang, K. R.; Chao, C. I.; Wei, P. K.; Fann, W. S., Conjugated polymer blends as emitting layer for white light led. Abstr Pap Am Chem S 1998, 215, U392-U392.

19. Goustouridis, D.; Manoli, K.; Chatzandroulis, S.; Sanopoulou, M.; Raptis, I., Characterization of polymer layers for silicon micromachined bilayer chemical sensors using white light interferometry. Sensor Actuat B-Chem 2005, 111, 549554.

20. Huang, J. S.; Li, G.; Wu, E.; Xu, Q. F.; Yang, Y., Achieving high-efficiency polymer white-light-emitting devices. Adv Mater 2006, 18, 114-117.

21. Kassamakov, I.; Ojala, K.; Salmia, A.; Haeggstrom, E.; Aaltonen, J.; Huber, A.; Saarikko, H.; Osterberg, M.; Oinonen, M., Characterization of dents and grooves on polymer films using scanning white light interferometry. Optical Microand Nanometrology in Microsystems Technology 2006, 6188. 
22. Kim, T. H.; Lee, H. K.; Park, O. O.; Chin, B. D.; Lee, S. H.; Kim, J. K., White-light-emitting diodes based on iridium complexes via efficient energy transfer from a conjugated polymer. Adv Funct Mater 2006, 16, 611-617.

23. Nicolai, H. T.; Hof, A. J.; Blom, P. W. M., Charge transport in white light-emitting polymers. Organic Optoelectronics and Photonics Ii 2006, 6192.

24. Chuang, C. Y.; Shih, P. I.; Chien, C. H.; Wu, F. I.; Shu, C. F., Bright-white light-emitting devices based on a single polymer exhibiting simultaneous blue, green, and red emissions. Macromolecules 2007, 40, 247-252.

25. Lee, P. I.; Hsu, S. L. C.; Lee, R. F., White-light-emitting diodes from single polymer systems based on polyfluorene copolymers end-capped with a dye. Polymer 2007, 48, 110-115.

26. Niu, Y. H.; Liu, M. S.; Ka, J. W.; Bardeker, J.; Zin, M. T.; Schofield, R.; Chi, Y.; Jen, A. K. Y., Crosslinkable hole-transport layer on conducting polymer for high-efficiency white polymer light-emitting diodes. Adv Mater 2007, 19, 300-+.

27. Chitara, B.; Bhat, S. V.; Vivekchand, S. R. C.; Gomathi, A.; Rao, C. N. R., White-light sources based on composites of gan nanocrystals with conducting polymers and nanophosphors. Solid State Commun 2008, 147, 409-413.

28. Liedtke, A.; O'Neill, M.; Wertmoller, A.; Kitney, S. P.; Kelly, S. M., White-light oleds using liquid crystal polymer networks. Chem Mater 2008, 20, 3579-3586.

29. Inoue, A.; Hosokawa, T.; Haishi, M.; Ohtani, N., 4-(dicyanomethylene)-2-methyl-6-(p-dimethylaminostyryl)-4hpyran $(\mathrm{dcm})$-doping density dependence of luminescence spectra and white emission in polymer light-emitting diodes. Physica Status Solidi C - Current Topics in Solid State Physics, Vol 6, No 1 2009, 6, 334-337.

30. Jeon, S. O.; Joo, C. W.; Yook, K.; Lee, J. Y., Color control of multilayer stacked white polymer light-emitting diodes using a quantum dot as an interlayer. Appl Phys Lett 2009, 94.

31. Cheng, G.; Fei, T.; Zhao, Y.; Ma, Y. G.; Liu, S. Y., White phosphorescent polymer light-emitting devices based on a wide band-gap polymer derived from 3,6-carbazole and tetraphenylsilane. Org Electron 2010, 11, 498-502.

32. Kim, S. H.; Jin, Y.; Yu, J. Y.; Kim, J.; Song, S.; Suh, H.; Lee, K., Color stable white polymer light-emitting diodes with single emission layer. Synthetic Met 2010, 160, 835-838.

33. Lee, P. I.; Hsu, S. L. C.; Lin, P. Y., White-light-emitting diodes from single polymer systems based on polyfluorene copolymers with quinoxaline derivatives. Macromolecules 2010, 43, 8051-8057.

34. Madhwal, D.; Rait, S. S.; Kumar, A.; Verma, A.; Tada, K.; Onoda, M.; Bhatnagar, P. K.; Mathur, P. C., Development and characterization of an efficient bio-white polymer light-emitting diode with red and green phosphorescent dyes as dopants. J Mater Sci 2010, 45, 3300-3303.

35. Hu, B.; Yao, C.; Huang, X. R., Designing of the white-light emission from a single-polymer system: Quantum theoretical study. Polym Sci Ser a+ 2011, 53, 1097-1105.

36. Lee, H. K.; Kim, T. H.; Park, J. H.; Kim, J. K.; Park, O. O., White-light-emitting diodes using miscible polymer blend doped with phosphorescent dye. Org Electron 2011, 12, 891-896.

37. Jeon, Y. P.; Choo, D. C.; Kim, T. W., Color tunable white organic light-emitting devices with a hybrid 2-methyl-9,10- 
di(2-naphthyl)anthracene small molecule/poly(2-methoxy-5-(2-ethyhexoxy)-1,4-phenylenevinylene) polymer emitting layer. Thin Solid Films 2012, 521, 189-192.

38. Meng, L. C.; Lou, Z. D.; Yang, S. Y.; Hou, Y. B.; Teng, F.; Liu, X. J.; Li, Y. B., White organic light-emitting diodes based on a combined electromer and monomer emission in doubly-doped polymers. Chinese Phys B 2012, 21.

39. Nicolai, H. T.; Hof, A.; Blom, P. W. M., Device physics of white polymer light-emitting diodes. Adv Funct Mater 2012, 22, 2040-2047.

40. Kim, J. H.; Song, W. S.; Yang, H., Color-converting bilayered composite plate of quantum-dot-polymer for high-color rendering white light-emitting diode. Opt Lett 2013, 38, 2885-2888.

41. Kuo, C. P.; Chuang, C. N.; Chang, C. L.; Leung, M. K.; Lian, H. Y.; Wu, K. C. W., White-light electrofluorescence switching from electrochemically convertible yellow and blue fluorescent conjugated polymers. J Mater Chem C 2013, 1, 2121-2130. 